\section{Emotional Lability}

Robert G. Frank

University of New Mexico,

Albuquerque, NM, USA

\section{Synonyms}

Emotional incontinence; Pathological laughing and crying

\section{Definition}

Emotional lability is defined as rapid emotional change, most often associated with changes in affect related to injury or neurological conditions. Lability is observed conditions such as CVA, traumatic brain injury, neurocognitive disorders, schizophrenia, bipolar disorder, or borderline personality disorder. When characterized by uncontrolled laughing and/or crying that is disproportionate to the situation, it is called as pseudobulbar affect. Pseudobulbar affect is a disinhibition syndrome associated with pathways involving of serotonin and glutamate, but the pathways are not fully understood. The difference between pathological crying and depression is not well defined. In general, depression is characterized by much longer duration. Pseudobulbar affect does not present with sleep disturbance or loss of appetite. Prevalence estimates vary from $9.4 \%$ to $37.5 \%$ indicating as many as 7.1 million Americans may be affected. Treatment with various antidepressant medications appears to be the most effective intervention.

\section{Cross-References}

- Pseudobulbar Affect

- Pseudobulbar Palsy

- Traumatic Brain Injury

\section{References and Reading}

Ahmed, A., \& Simmons, Z. (2013). Pseudobulbar affect: Prevalence and management. Therapeutics and Clinical Risk Management, 9, 483-489. https://doi. org/10.2147/TCRM.S53906.

Caplan, B. (2009). Rehabilitation psychology and neuropsychology with stroke survivors. In R. G. Frank, M. Rosenthal, \& B. Caplan (Eds.), Handbook of rehabilitation psychology (2nd ed., pp. 63-94). Washington, DC: American Psychological Association.

Morris, P., Robinson, R. G., \& Raphael, B. (1993). Emotional lability after stroke. Australian and New Zealand Journal of Psychiatry, 27(4), 601-605.

Silver, J., Arciniegas, D., \& Yudovsky, S. (2005). Psychopharmacology. In J. Silver, T. McAllister, \& S. Yudovsky (Eds.), Textbook of traumatic brain injury. Arlington: American Psychiatric. 